\title{
Sensitivity Experiments of the Local Wildland Fire with WRF-Fire Module
}

\author{
Shaojun Lai ${ }^{1,2,3}$ (10) Haishan Chen ${ }^{2,3} \cdot$ Fen He $^{4} \cdot$ Weijie $\mathrm{Wu}^{5}$
}

Received: 1 April 2019 / Revised: 29 October 2019 / Accepted: 7 November 2019 / Published online: 4 December 2019

(C) The Author(s) 2019

\begin{abstract}
In this paper, it is discussed the performance of the Weather Research and Forecasting (WRF) model coupled with a wildland firebehavior module (WRF-Fire model) by the observational data collected in an experiment with a low-intensity prescribed fire (LIPF) conducted in the New Jersey Pine Barrens (NJPB) on March 6, 2012. The sensitivity experiments of the WRF-Fire model are carried out to investigate the interactions between the wildland fire and the atmospheric planetary boundary layer. The twoway WRF-Fire model conofigured with fire and large eddy simulation (LES) mode is used to explore the fire characteristics of perimeter shape, intensity, spread direction and external factors of wind speed, and to discuss how these external parameters affect the fire, and the interactions between the atmosphere and fire. Results show that the sensitive experiments can provide the meteorological elements close to observations, such as the temperatures, winds and turbulent kinetic energy near the surface in the vicinity of the fire. The simulations also can reproduce the fire spread shape and speed, fire intensity, and heat flux released from fire. From the view of energy, the heat flux feed back to the atmospheric model and heat the air near the surface, which will induce strong thermal and dynamic instability causing strong horizontal convergence and updraft, and form the fire-induced convective boundary layer. The updraft will be tilted downstream of the fire area based on the height of the ambient winds. Due to the effect of the this updrafts, the particles and heat from the fuel combustion can be transported to the downwind and lateral regions of the fire area. Meanwhile, there is a downdraft flow with higher momentum nearby the fire line transporting fresh oxygen to the near surface, which will increase winds behind the fire line, accelerate the rate of spread (ROS) and make the fire spread to a larger area. Ultimately, a fire-induced climate is established.
\end{abstract}

Keywords WRF-fire $\cdot$ Wildland fire $\cdot$ Large Eddy simulation $\cdot$ Turbulent kinetic energy $\cdot$ Surface heat flux

\section{Introduction}

Wildfires occur as a natural part of the endless cycle of nature, affect the lives of millions of people and cause major property

Responsible Editor: Ben Jong-Dao Jou.

Shaojun Lai

cyclesj@163.com

1 Fuzhou Meteorological Bureau, Fuzhou 350008, China

2 Key Laboratory of Meteorological Disaster of Ministry of Education, Nanjing University of Information Science \& Technology, Nanjing 210044, China

3 College of Atmospheric Science, Nanjing University of Information Science \& Technology, Nanjing 210044, China

4 Fujian Climate Center, Fuzhou 350001, China

5 Xiamen Meteorological Bureau, Xiamen, China damage every year worldwide. Wildland fire effects include ecological and hydrological impacts on the landscape, the percentage of forest fuel consumed in prescribed fires, tree mortality, soil impacts and air-quality impacts, for example, the emission rate, components and cumulative quantity of smoke produced. With the rapid advances in computing technologies and the accurate description of the physical processes, significant advances have been made in coupled atmosphere-fire numerical models to simulate the behavior of wildland fire and its interactions with the atmosphere. However, the accurate representation of the wildfire process remains a significant challenge because wildfires are a complex phenomenon that involves multi-physics and multi-scale processes and are easily affected by interactions with other land surface processes.

Wildland fire behavior is broadly defined by the manner in which fuel ignites, flame develops and fire spreads, and the behavior exhibits other related phenomena, as determined by 
the interactions of a fire with its environment, i.e., fuels, weather and topography. The difficulty in predicting wildland fire behavior is due to uncertainties that are associated with the inherent variation in fuels, weather and topography both in time and in space. Over the past two decades, a number of studies (Clark et al. 1996a; Morvan et al. 2002; Coen 2005; Sun et al. 2006; Mell et al. 2007) have used a coupled atmosphere-fire model to investigate the dynamics of fireatmosphere interactions. Most of these previous studies, however, are limited to idealized cases. The accuracy and uncertainties of these models have not been adequately documented, due largely to the lack of appropriate observational datasets, which place significant limitations on their usage and further improvement. Prescribed fire is applied to reduce hazardous fuels in Southern Forests each year for various forest, range and agricultural purposes (USDA Forest Service 1989). Low-intensity prescribed fire (LIPF) is the most effective and efficient technique to reduce both the quantity and suspension of fuel (Hunt and Simpson 1985) and can be viable tools to maintain biodiversity, mitigate the severity of bushfires, rehabilitate vegetations. Furthermore, observational data collected during LIPF experiments can be used to undertake research on fire and its interactions with our environment, espercially to evaluate and improve the simulation of fire behavior models.

The Weather Research and Forecast (WRF) model (Skamarock et al. 2008), developed mainly at the National Center for Atmospheric Research and the National Oceanic and Atmospheric Administration, is portable and computationally efficient on a variety of platforms. The WRF is a community model that is being increasingly used to study atmospheric dynamics and land-atmosphere interaction at various scales. Some of the appealing features of the model simulations, in particular its nesting capabilities, is designed to run on massively parallel computers, as well as the availability of real-world land-use and topography data and of regionalscale meteorological forcing data that are easily imported into the model. The two-way nested WRF model can provide meteorological elements at high spatial and temporal resolutions to satisfy users with different demands and accommodate multiple embedded grids to gradually scale down the resolution to that characteristic of turbulent motion. Moeng et al. (2007) captured many characteristics of the turbulence at the atmospheric boundary layer (ABL) using the WRF model.

The coupled WRF and SFIRE model, which was called WRF-Fire by Patton and Coen (2004), originated from NCAR's CAWFE code (Clark et al. 1996a, b, 2004; Coen 2005), which combines the Clark-Hall mesoscale atmospheric model and a tracer-based fire spread model. However, the Clark-Hall model is a serial code and is difficult to modify or use for real cases that require real atmospheric background, topography and fuel category data; however, all of these data can be accommodated in the WRF model. WRF-Fire (Mandel et al. 2007, 2011), which combines the WRF model with a semi-empirical fire spread model, calculates the rate of the spread of a fire line according to the fuel categories, wind velocity and terrain slope in the normal WRF model. The two-way coupling of the WRF-Fire model enables research on the feedback and interactions between the fire environment and atmosphere near the fire, which helps us to explore how a fire creates its own weather. The winds and humidity from the atmospheric module are interpolated into the WRF-Fire model, along with fuel properties and local topographic features, and then the fuel consumption and the energy calculated by the fire spread module as the sensible and latent heat are fed back into the atmospheric model (Mandel et al. 2011; Coen et al. 2013).

There are different scales of turbulent eddies within the planetary boundary layer (PBL). Large eddies (from approximately $100 \mathrm{~m}$ to $1000 \mathrm{~m}$ or larger) are produced directly by the instability of the mean flow and small eddies, while small eddies (from a few centimeters to $100 \mathrm{~m}$ ) are produced by the larger eddies in the energy-cascade process. Simple ensemblemean turbulence models (i.e., parameterization schemes) are unable to forecast the details of the airflow at this resolution because their closure assumptions and constants are based on laboratory airflow data or solutions of horizontally homogenous PBLs. It is of critical importance to describe and understand the problems that involve the PBL at resolutions less than $100 \mathrm{~m}$. At that scale, the viscous forces are dominant, and the effect of the smaller eddies is to dissipate the turbulent energy rather than to transfer momentum and heat. The mesoscale atmospheric model, which has a grid resolution usually larger than $1 \mathrm{~km}$, cannot easily capture the detailed structural variations of meteorological dynamical and land-atmosphere exchanges, especially over complex topography. Deardorff (1972) first attempts the large-eddy simulation (LES) approach and obtains many useful insights into the turbulent structure of the PBL. The influence of the small-scale eddies is usually represented by turbulence closure, which is similar to a fairly conventional ensemble-mean turbulence closure in terms of concept, but the latter is applied to an average length scale and is appropriate for the unresolved motions. An LES involves the explicit numerical representation of the largescale eddies and the parameterization of small-scale eddies in the flow (Mason 1989) and resolves energy-containing turbulent motions that are responsible for most of the turbulent transport. Deardorff (1974) and Moeng (1984) have successfully captured and resolved the features of large eddies. Patton and Coen (2004) proposed and formulated that the innermost domain of the fire should be run in the LES mode. Mandel et al. (2011) suggested that if the resolution of the domain is less than $100 \mathrm{~m}$, the domain should actually be resolved in the LES mode to distinguish the most energetic eddies that are responsible for mixture within the boundary layer. Sun et al. (2009) examined the differences in the ROS and area burnt of 
grass fire in two types of ABL by using the coupled UU-LES (University of Utah's Largescale Eddy Simulation) model. They found the type of ABL convection affected directly the variability in burnt area, spread rate, and shape of fire lines, and owing to random flow interactions, indirectly the strength of fire-induced convection. Some studies investigate the turbulence-resolving large eddy simulation mode of WRF (WRF-LES) in idealized simulations with no coupling to mesoscale simulations or real-world meteorological forcing. Coen et al. (2013) proceed idealized simulations using WRF-Fire with LES mode to test the sensitivity of the wildland fire behavior to environmental factors. The simulations were designed with fully boundary layer turbulence generated through the momentum and heat exchange, and considered the dynamic interactions between the fire-generated winds and coherent atmospheric turbulent motions.

Recent studies (Mandel et al. 2011; Coen et al. 2013) have used WRF-Fire to discuss the sensitivity of simulated fire characteristics. Kondratenko et al. (2011) created an approximate artificial history of the fire and replayed the fire history and output heat fluxes allowing the atmospheric circulation development. Mandel et al. (2014) developed new data assimulation system in WRF-SFIRE, described smoke dispersion and air quality with WRF-Chem, and gave an operational example in Israel. The LIPF experiment provides a unique opportunity to evaluate WRF-Fire in LES mode and study the interactions between a wildland fire and the lowest atmosphere using the measurements. The purposes of this paper are 1) to evaluate the performance of the coupled WRF-Fire model by performing a series of realistic numerical simulations, 2) to improve our understanding of the interactions between the PBL atmospheric environment and wildland fire and their changing characteristics during wildland fires, and 3) to analysis the mechanisms of the flow propagation that is induced by wildland fire within the near surface layer.

The LIPF experiment and the configuration and experimental design of the WRF-FIRE model are introduced in Section 2. The data used in the paper are discussed in Section 3. An introduction to the LIPF experiment, synoptic pattern and the results of the evaluations of the WRF-Fire model simulations and the mechanisms of interaction of the wildland fire and atmosphere are presented in Section 4. The paper is summarized and concluded in Section 5.

\section{Model Configuration and Parameterization}

The WRF-Fire model in version 3.3 is used in this study. Four model domains with two-way nesting are used with grid spacings of 6250, 1250, 250 and $50 \mathrm{~m}$, and LES mode configuration is activated only in finest domain. The detailed configurations of the WRF-FIRE modeling domains are given in Table 1. All of the domains are centered at coordinates
Table 1 WRF-Fire model domain configurations

\begin{tabular}{lllll}
\hline Domains & D01 & D02 & D03 & D04 \\
\hline Resolution (meters) & 6250 & 1250 & 250 & 50 \\
Grid Points (E-W) & 81 & 101 & 71 & 81 \\
Grid Points (N-S) & 81 & 101 & 71 & 81 \\
Vertical layers & 43 & 43 & 43 & 43 \\
Time steps (second) & 20 & 6.67 & 2.22 & 0.74 \\
\hline
\end{tabular}

$\left(74^{\circ} 36^{\prime} 26.93^{\prime \prime} \mathrm{W}, 39^{\circ} 54^{\prime} 39.14^{\prime \prime} \mathrm{N}\right)$. The outermost domain (D01) encompasses the northeast United States and a portion of northwestern Atlantic Ocean (Fig. 1a). The smallest domain (D04) covers an area of approximately $4 \times 4 \mathrm{~km}^{2}$ centered over the location of the LIPF experiment (Fig. 1b). There are 43 sigma vertical levels, 17 of them are within the 0.9 sigma layer with the lowest level at about $7 \mathrm{~m}$ above ground level (AGL) to provide an enhanced resolution in the planet boundary layer (PBL). A 20-s time step is used for the outermost domain. In the innermost grid, the fire mesh is 10 times finer than the atmospheric mesh to allow for gradual heat release into the atmosphere, even if fuel and topography data might not be available at such fine resolution (Mandel et al. 2011).

The North American Regional Reanalysis (NARR) data (Mesinger et al. 2006) from the National Centers for Environmental Prediction (NCEP) are used for the meteorological initial and lateral boundary conditions. The datasets have $32 \mathrm{~km}$ horizontal resolutions and 45 vertical levels with a fully cycled 3-h Eta Data Assimilation System (EDAS).

The highest resolution of the default geographic data are too coarse to run the WRF-Fire model. The Landfire website (http://landfire.cr.usgs.gov/viewer/) provides us with the 13category Anderson fuel model data (Anderson 1982) and the topography elevation data at $30 \mathrm{~m}$ resolution to perform the fire simulation. Figure $1 \mathrm{c}$ and $\mathrm{d}$ show the fuel categories and the topography elevation data at the $30 \mathrm{~m}$ resolution of the smallest domain. From these data, the primary fuel in the fire area are brush, hardwood slash and some timber litters (Fig. $1 \mathrm{c})$, and there is a down slope to the north of the ridge and a valley on the right side of the fire location (Fig. 1d).

The physical parameterization schemes used in all of the model domains are the Dudhia shortwave radiation (Dudhia 1989), rapid radiative transfer model (RRTM) longwave radiation (Mlawer et al. 1997), WRF Single-Moment 6-class (WSM6) microphysics (Hong et al. 2004), Monin-Obukhov (Janjic Eta) surface layer scheme (Janjic 1994, 2001), Noah land surface scheme (Chen and Dudhia 2001). The MYJ PBL scheme (Janjic 1990, 1994, 2001) is used in the first three domains, and in the finest domain (D04) the large-eddy simulation option is actived. The diffusion in physical space is the full diffusion scheme, and the eddy viscosities are calculated using a $3 \mathrm{D}$ prognostic 1.5 -order turbulence closure for the 

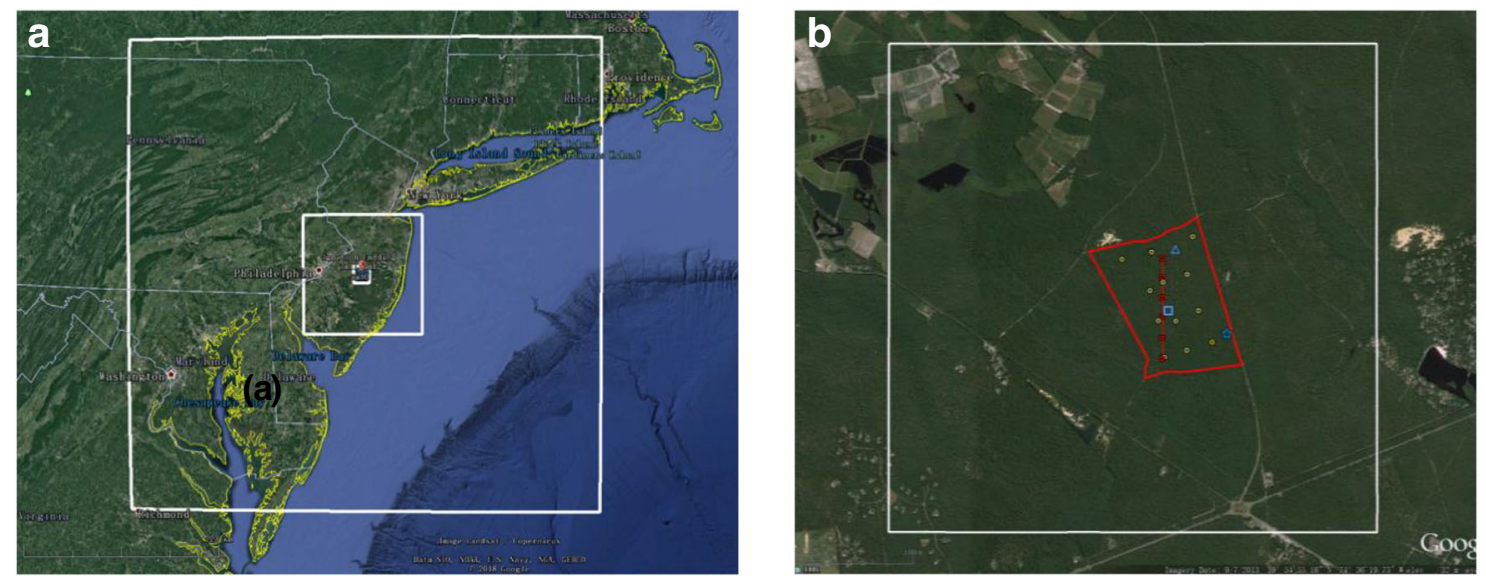

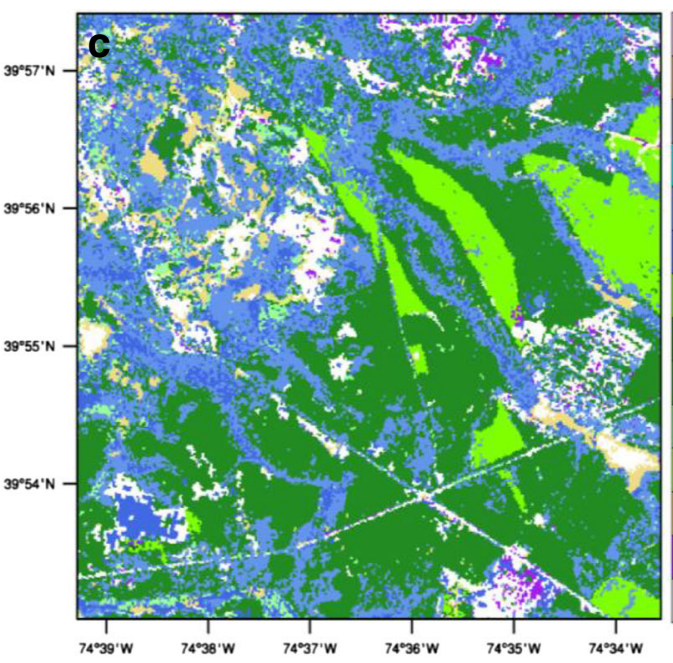

Fig. 1 Position of the first two model domains (Fig. 1a), and the inner most domains and fire area of the LIPF experiment overlaied with $3-\mathrm{m}$ towers (yellow circles), 10-m tower (blue triangle), 20-m tower (bule

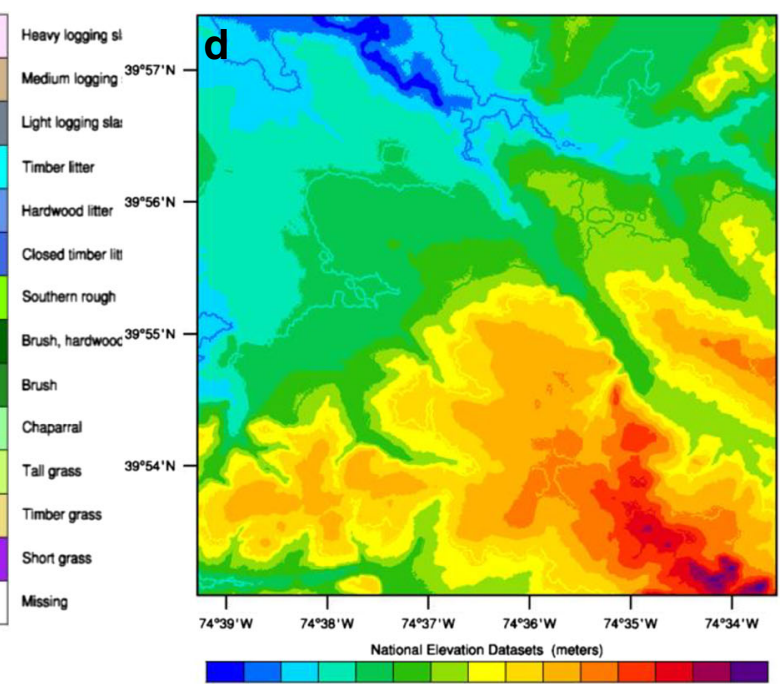

$\begin{array}{llllllllllllll}12.5 & 15 & 17.5 & 20 & 22.5 & 25 & 27.5 & 30 & 32.5 & 35 & 37.5 & 40 & 42.5 & 45\end{array}$

square), 30-m tower (blue star) (Fig. 1b), the fuel categories (Fig. 1c) and the terrain elevation (Fig. 1d) of the finest domain (D04)

the first ignition point at the southwest of the burn area (Fig. $1 b)$.

\section{Experiment and Data}

The LIPF experiment was conducted on March 62,012 in the New Jersey Pine Barrens (NJPB) (centered in $39.9141^{\circ} \mathrm{N}$, $\left.74.6033^{\circ} \mathrm{W}\right)$. Three observational towers with measurements at the height of 10-, 20-, and 30-m were located inside the fire area. In addition, twelve 3-m towers were set up to observe the meteorological elements near surface. In this paper, only data from the instrumentations on the 10-, 20- and 30-m were utilized. Table 4 provided all the information about the observation devices and instruments on the towers of the LIPF. The fire was ignited at 15:00 UTC Mar. 6, 2012, when the ambient flow was northwesterly, and the fire line spread to southeast. As the wind veered to west and then to south at approximately 19:00 UTC, the fire spread rapidly to the north and combusted 
vigorously. With the fuels consumed, the speed of fire spread slowed down with the combustion gradually extinguished after 21:00 UTC. It approximately last $10 \mathrm{~h}$ from the ignition to extinguishment. More detailed descriptions about the LIPF experiment could be found in Heilman et al. (2013).

The quality control steps of the observations collected from the LIPF experiment including the despiking, data filtering, were applied in the paper. The perturbation of velocities $(u$, $\left.v^{\prime}, w^{\prime}\right)$ and temperatures $\left(t^{\prime}\right)$ were computed from average values of wind and temperature data after quality controled for one hour period, thus the turbulent kenetic energy (TKE), turbulent heat flux, and other turbulent variables could be derived from the perturbation data. The results of the finest domain from 06:00 UTC, Mar. 6 to 06:00 UTC, Mar. 7 were qualitatively compared with the data collected from the 3 meteorological towers in the burn area.

\section{Results}

\subsection{Synoptic Pattern Retrospect}

The synoptic system and its variation were very stable and simple during the LIPF experiment, which was a necessary and important condition for excuting the fire experiment. From the NARR data, the NJPB was located in the front of a ridge during the course of the experiment a height of $500 \mathrm{~h} \mathrm{~Pa}$ (figure omitted). Meanwhile, at the surface level, a low-pressure system was located in the northwest Atlantic Ocean and a high-pressure system was located west of the Appalachia Mountains from the Great Lakes extending south to South Carolina. The wind was steady from the northwest at 06:00 UTC, Mar. 6 (Fig. 2a). When the ignition began at 15:00 UTC, Mar. 6 (Fig. 2b), the center of high pressure was over North Carolina and South Carolina, and the low pressure system was moving slowly to the northeast. At 18:00 (Fig. 2c), Mar. 6, the high pressure system weakened and moved to the south of New Jersey, the wind direction gradually turned from northeastern wind to westerly wind. At 21:00 (figure omitted), there was a large region with a southerly wind west of New Jersey. At 00:00, Mar. 7 (Fig. 2d), the high pressure system moved to the Atlantic Ocean, and the wind approximately veered to the south or southwest at the fire experiment area.

Figure 3 presents the vertical soundings on the skew T-log diagrams compared with the control simulation (NFNL case) at Brookhaven, New York (OKX) at 0000 UTC 7 May (Fig.3a,b), and 1200 UTC 7 May (Fig.3c,d). As shown in Fig. 3, the WRF model not only simulates the temperatue and drew point temperature, espercially the inversion layers, as the observations displaying, but also captures the wind profiles shifting at different times.

\subsection{Wind}

Wind is one of the most important and rapidly changing environmental factors that influence fire behavior, the higher wind speeds produce larger fire spreading rates over a wide range of wind speeds and fuels (Coen et al. 2013). Because of the interaction between the fire and the atmosphere, the timeaveraged wind at ABL does not necessarily to represent the same effect on the fire spread and intensity as the ABL turbulent flow does over the same period. A sudden change of the ABL winds will subsequently change the fire behavior (Sun et al. 2009). A rise in the ambient wind speed undoubtedly increases the speed of fire spread, and the direction of the spreading fire line will be affected by the fresh fuel along its perimeter.

Figure 4 demonstrates the vertical profiles of winds of the NFNL case and observations at 10-, 20-, and 30-m,

Table 2 Physics parameterization schemes of the simulated experiments

\begin{tabular}{|c|c|c|c|c|}
\hline $\begin{array}{l}\text { Domains } \\
\text { Physics options }\end{array}$ & D01 & D02 & D03 & D04 \\
\hline Shortwave radiation & Dudhia & Dudhia & Dudhia & Dudhia \\
\hline Longwave radiation & RRTM & RRTM & RRTM & RRTM \\
\hline Microphysics & WSM6 & WSM6 & WSM6 & WSM6 \\
\hline Surface layer & Eta similarity & Eta similarity & Eta similarity & Eta similarity \\
\hline Land surface & Noah & Noah & Noah & Noah \\
\hline PBL scheme & MYJ & MYJ & MYJ & None \\
\hline LES PBL & None & None & None & Yes \\
\hline Cumulus parameterization & Kain-Fritsch & None & None & None \\
\hline Diffusion Option & Full diffusion & Full diffusion & Full diffusion & Full diffusion \\
\hline K Option & 3D TKE & 3D TKE & 3D TKE & 3D TKE \\
\hline Slope and shading effects & None & Yes & Yes & Yes \\
\hline
\end{tabular}


Table 3 List of the numerical schemes in the simulations

\begin{tabular}{llc}
\hline Simulations cases & Fire & LES \\
\hline No Fire No LES (NFNL) & No & No \\
No Fire With LES (NFWL) & No & Yes \\
With Fire No LES (WFNL) & Yes & No \\
With Fire With LES (WFWL) & Yes & Yes \\
\hline
\end{tabular}

respectively. From the figure, both the horizontal or vertical profiles and theirs variation trends of the simulations are similar to the observations, with a little overestimation in wind speed at 10-m height. The distribution of wind directions at $20-$, and $30-\mathrm{m}$ matches the observations well, but the gap is about $30^{\circ}$ at the $10-\mathrm{m}$ level.

Figure 5 shows the wind speeds and directions time series comparison of all simulations and observations. The winds below $20 \mathrm{~m}$ AGL are much smaller due to the roughness of the bushes and the tree crowns. The winds blow from the northwest at the beginning of experiment, then shift to the south slowly and last about $15 \mathrm{~h}$ till the end of the experiment, which proves the simulated wind directions fitted with the observations well. The mean absolute errors of wind directions between simulations and observations are about 19 and 35 degrees at height of 20 - and $30-\mathrm{m}$ respectively, and the WFWL case performs the best in wind directions simulation (Table 5). As for the wind speed, the observed winds at $30 \mathrm{~m}$ $(2.8 \mathrm{~m} / \mathrm{s}$ in average $)$ are a bit larger than those at $20 \mathrm{~m}(1.9 \mathrm{~m} / \mathrm{s}$ in average). The wind speeds from the cases with LES are larger than the cases without LES, and the winds from the cases with fire have more uniform disturbance unlike big disturbance of those without fire, which agree with the observations behavior more.

The figure also indicates that WRF-Fire provides reasonable results of the winds from the model comparing with the observations at $20 \mathrm{~m}$ and $30 \mathrm{~m}$ height.

\subsection{Temperature}

The simulated temperatures averaged from 1500 to 2200 UTC, Mar. 6 near the fire area are compared with the observations at 10-, 20-, and 30-m height (figure not shown). From the figure, the temperature difference between simulation and observation is less than $5 \%$ at 10 - and $20 \mathrm{-m}$ levels, but the simulation is about $17 \%$ greater than observations at 30-m high.

The simulated temperature time series at various heights are compared with the observations in Fig. 6. As seen in the figure, the simulated temperatures are somewhat underestimated and more smoothness prior to the fire ignition. In the view point of numerical value, the simulated temperatures with the fire are the biggest, the observations are the second, and the simulations without the fire are the minimum, except for the skin temperatures, after the fire starting. The simulated temperatures with fire are more close to the observations, espercially in higher levels (Table 5). Moreover, there are more perturbations and peaks in the simulated temperature curves with LES option than the observations and simulations without LES, and the number of temperature perturbations and the peak values increase with increasing of height. For example, at a height of $20 \mathrm{~m}$, the temperature peak value of the WFWL case in fire area has approximately increased by a third than the observations, but the disturbances are smaller at the lower height. It is reasonable that the fuels in the LIPF experiment are primarily bush or hardwoods several meters high, so the high temperature core increases to higher levels easily as the fire proceeding.

\subsection{Propagation of Fire}

In the LIPF experiment, the fire was ignited at 15:00 UTC Mar. 6. At 16:00 UTC, the fire spread to the southeast with the northwesterly ambient wind flow (Fig. 7a). When the direction of the wind became southerly at approximately 19:00 UTC (Fig. 7b), the fire spread rapidly to the north and combusted vigorously. As the fuels were consumed, the fire slowed and the combustion was gradually extinguished after 21:00 UTC (Fig. 7c). Figure 7d shows the fire spread perimeters of WFWL case at different times with 30-min intervals. The fire spread perimeters show that the fire isochrones are closer together in the direction again the wind and farther apart in the downwind. The ROS is closely connected with the wind

Table 4 Summary of instrumentations used in 10-, 20-, and 30-m towers

\begin{tabular}{lllll}
\hline Tower (meter) & Instrument & Varibles & Instument height (meter) & Sampling frequency (Hz) \\
\hline 10 & 3D anemomenters (R. M. Young 81,000 V) & $u, v, w, T$ & 3,10 & 10 \\
10 & Temperature-RH probes (Vaisala HMP50) & Mean T, RH & 3,10 & 10 \\
20 & 3D anemomenters (R. M. Young 81,000 V) & $u, v, w, T$ & $3,10,20$ & 10 \\
20 & Temperature-RH probes (Vaisala HMP50) & Mean T, RH & $3,10,20$ & 10 \\
30 & 3D anemomenters (R. M. Young 81,000 V) & $u, v, w, T$ & $3,10,30$ & 10 \\
30 & Temperature-RH probes (Vaisala HMP50) & Mean T, RH & $3,10,30$ & 10 \\
\hline
\end{tabular}



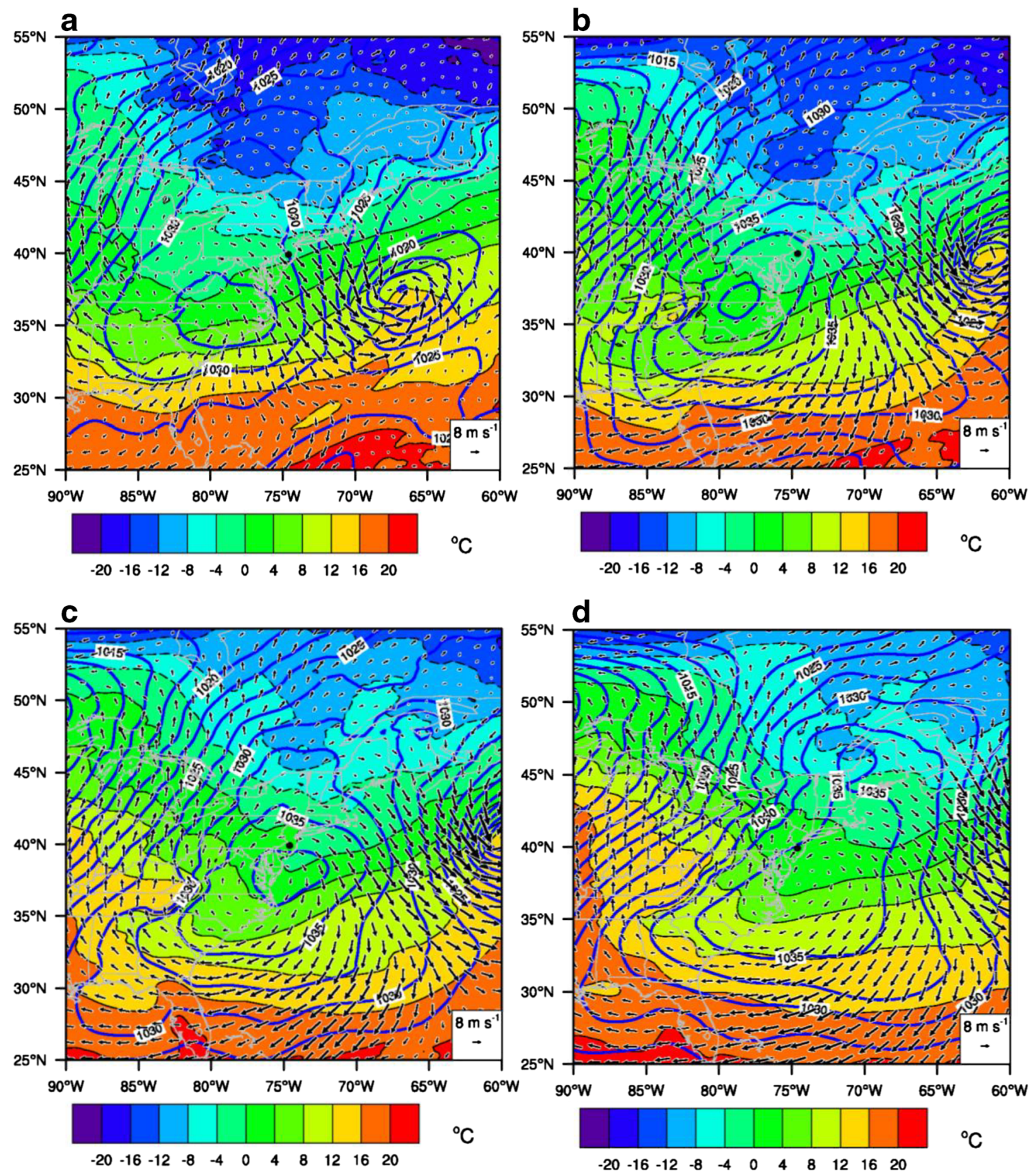

Fig. 2 The synoptic pattern variation during the LIPF experiment (the contours are sea level pressure, unit: $\mathrm{h} \mathrm{Pa}$, and temperature (shaded), unit: ${ }^{\circ} \mathrm{C}$, arrow is wind, unit: $\mathrm{m} / \mathrm{s}$, black dot indicates the location of the LIPF

experiment). (a. 06:00 UTC, Mar. 6, 2012, b.15:00 UTC, Mar. 6, 2012, c.18:00 UTC, Mar. 6, 2012, d.00:00 UTC, Mar. 7, 2012)

oscillations, a rising in ambient wind speeds or turbulances will increase the spread rate of the fire line contacting fresh fuel and air along its perimeter. At the mean time, the ROS is more faster in the northeast of the LIPF region, where there is a downslope terrain.

\subsection{Turbulent Kinetic Energy (TKE)}

Turbulent kinetic energy is one of the most important variables in micrometeorology and is a measure of the

intensity of turbulence. However, TKE is quickly generated and dissipated. It is almost impossible that the TKE from the model output will be exactly consistent with that calculated from the observations. Heilman and Bian (2010) conducted an initial study on the feasibility of predicting the near-surface TKE using a mesoscale model. In this paper, the resolution of the simulations is fine enough to resolve the turbulent energy transport motions, and a histogram is chosen as a graphical representation of the tabulated frequencies and used to estimate 
Fig. 3 The skew T-log diagrams comparison of rawinsonde sounding ((a), (c)) and WRF-Fire control case $((\mathbf{b}),(\mathbf{d}))$ at Brookhaven, New York (OKX). (a) and (b) 00:00 UTC, Mar. 7, 2012, (c) and (d) 12:00 UTC,

Mar. 7, 2012
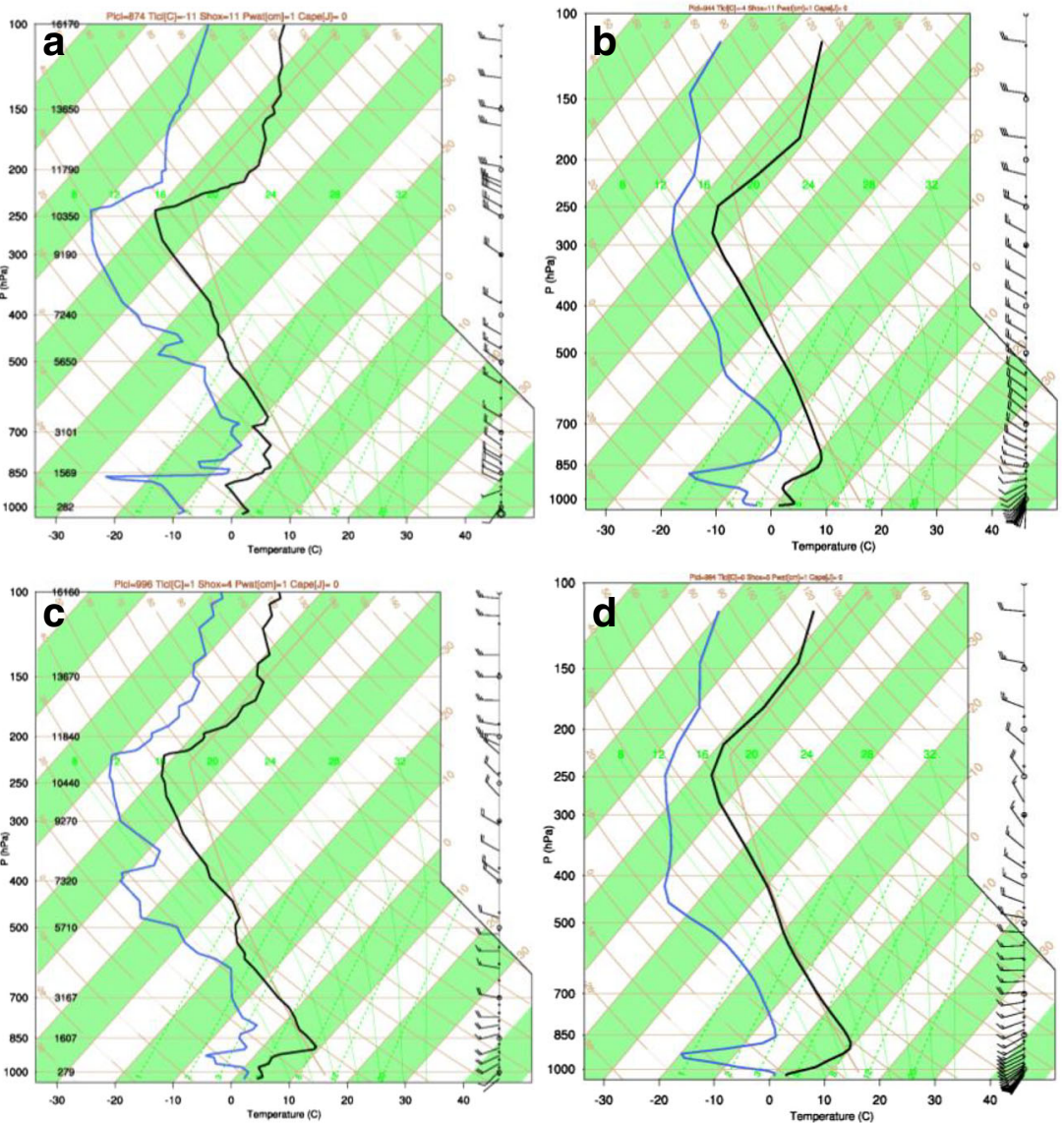

the probability distribution of a continuous variable. To calculated the TKE, the 3-dimensional winds are averaged over 1-m period in 3 directions separately; the perturbation winds $\left(u^{\prime}, v^{\prime}, w^{\prime}\right)$ substracts the average winds in the same period to obtain the instantaneous winds value; the TKE is subsequently computed as $1 / 2\left(u^{\prime 2}+v^{\prime 2}+w^{\prime 2}\right)$.
For the simulations, the resolution of the WRF-Fire model was fine enough to resolve the turbulent energy transport motion. Figure 8 shows comparisons of the observed and modeled frequency distributions of the TKE at $20 \mathrm{~m}$ and $30 \mathrm{~m}$ AGL. From the figure, over $90 \%$ of the TKE of all cases are less than $5 \mathrm{~m} 2 \mathrm{~s}-2$ and more than half of TKE's value

Fig. 4 Comparison of wind speed, wind direction and vertical velocity profiles averaged from 1500 to 2200 UTC Mar 6, 2012 between observations (markers) and NFNL case (lines) at 10-, 20-, and $30-\mathrm{m}$ height from towers. a red solid line and open circles are wind speed, blue dot line and stars are wind direction. $\mathbf{b}$ vertical velocity
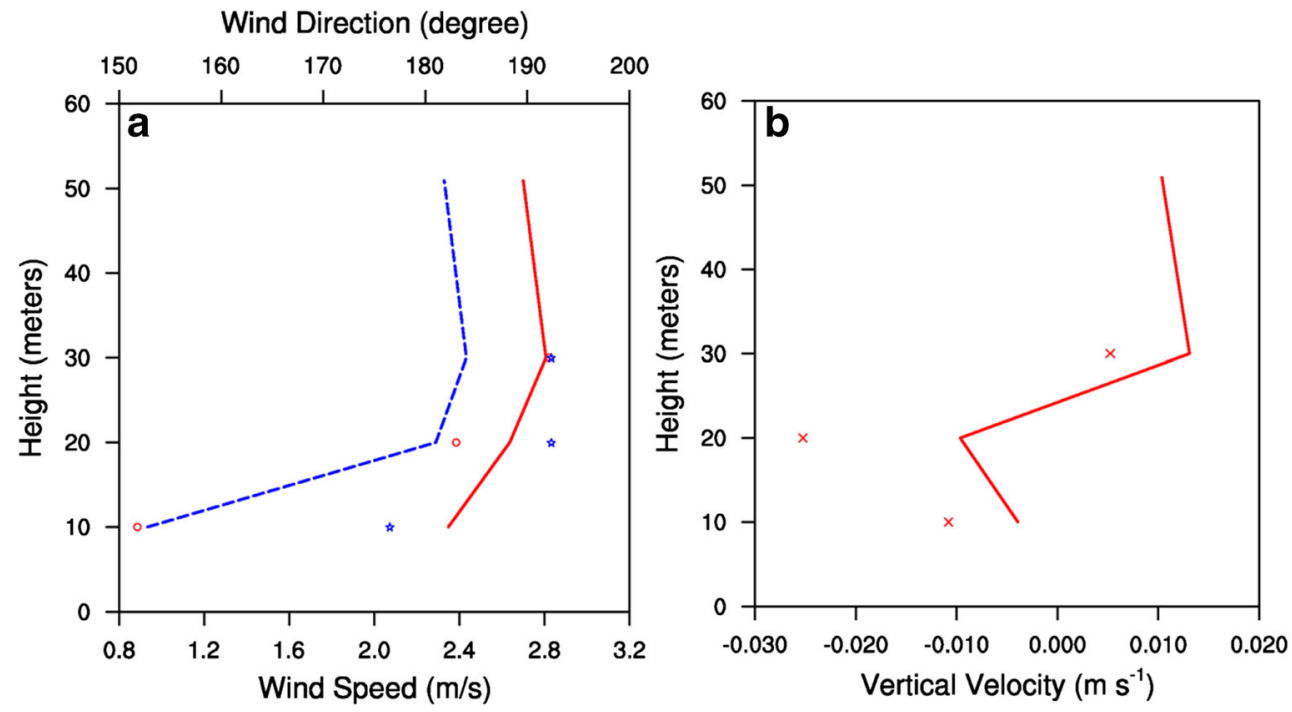

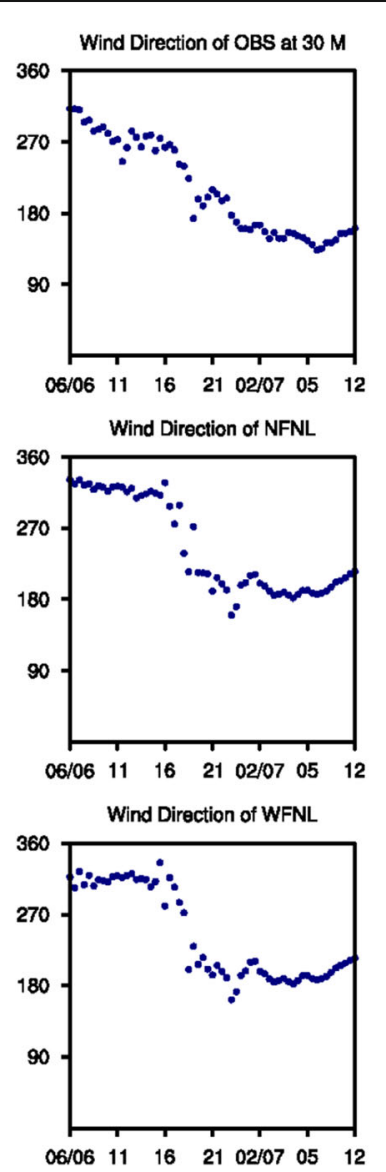

Fig. 5 The time series of wind speed and wind direction comparison between observations and simulated cases. The observations (the first row) are at 20 (right two figures) and 30 (left two figures) meters AGL.

distribution are below $1 \mathrm{~m} 2 \mathrm{~s}-2$. For the simulations without LES, the frequency of TKE's values less than $1 \mathrm{~m} 2 \mathrm{~s}-2$ has approximately $10 \%$ different from the observations, espercially at $30 \mathrm{~m}$ high. The gaps are narrowed significantly in cases with LES, except for somewhat overestimating in values greater than $5 \mathrm{~m} 2 \mathrm{~s}-2$. We also can find that the distributions of the TKE are mainly located in the range less than 5 $\mathrm{m} 2 \mathrm{~s}-2$, and the LES mode not only captured the primary distribution characteristics of the TKE but was also more consistent with the observations.

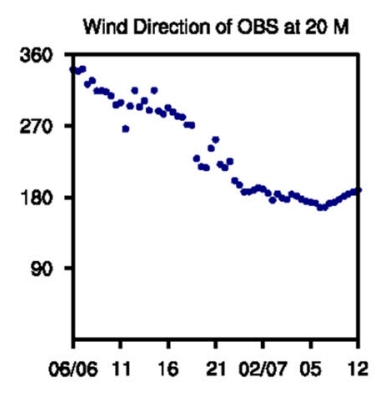

Wind Direction of NFWL

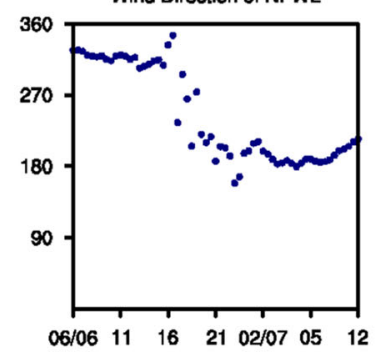

Wind Direction of WFWL
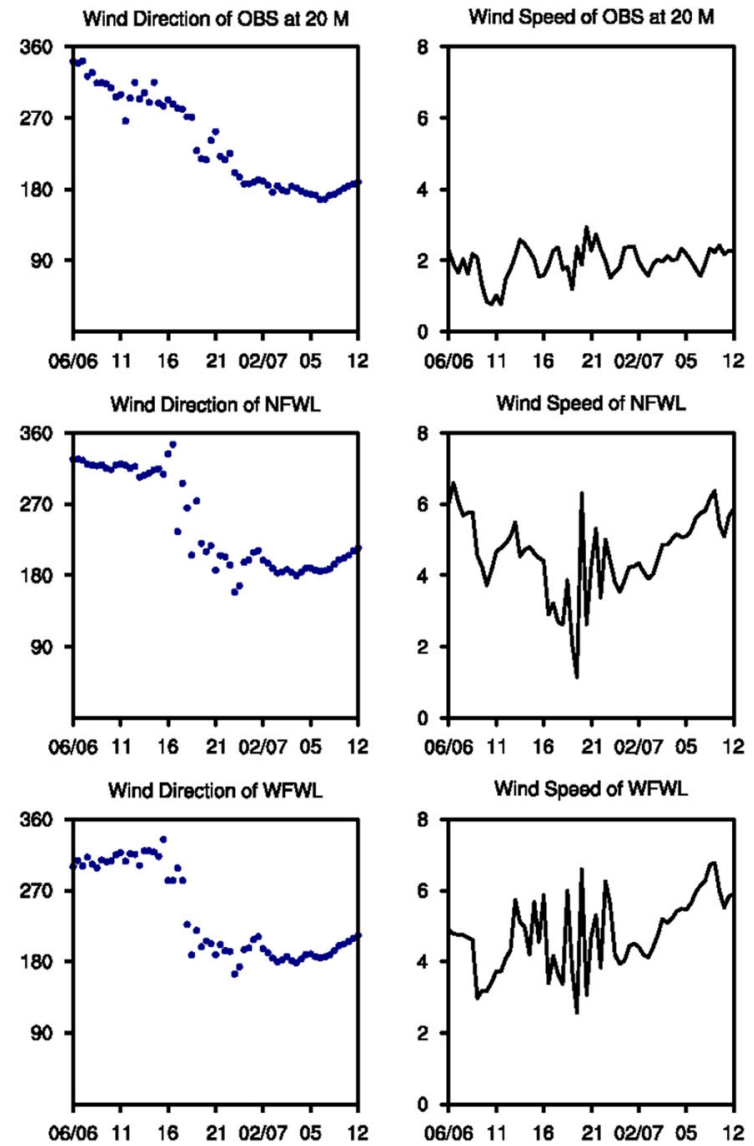

Wind Speed of NFWL

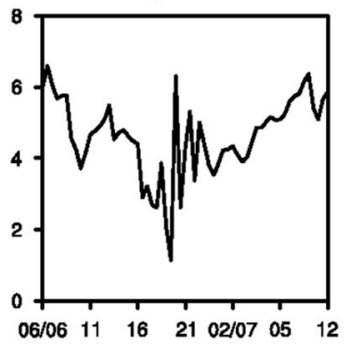

Wind Speed of WFWL

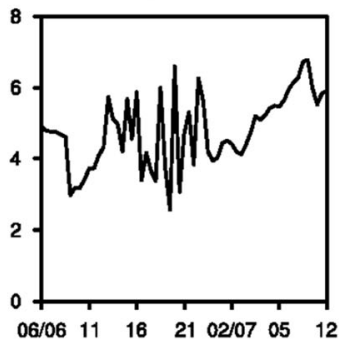

The simulated winds of all cases at about $22 \mathrm{~m}$ AGL are in the second and third rows respectively

\subsection{Interactions between the Fire and Atmosphere}

Horizontal convective rolls (HCRs) are one of the most common features of boundary-layer convection and play an important role in the vertical transport of momentum, heat, moisture and air pollutants within the PBL. Weckwerth et al. (1997) described two categories of theories that lead to horizontal convective rolls: thermal instability and dynamical instability. The energy rolls of thermal instability were obtained from buoyancy and from the along-roll shear component for
Table 5 The simulated winds mean absolute errors with observations

\begin{tabular}{llllll}
\hline & Height & NFNL & NFWL & WFNL & WFWL \\
\hline Wind Speed (Unit:meter) & $20-\mathrm{m}$ & 2.09 & 2.73 & 1.98 & 2.82 \\
& $30-\mathrm{m}$ & 1.39 & 1.95 & 1.25 & 2.04 \\
Wind Direction (Unit:degree) & $20-\mathrm{m}$ & 18.27 & 18.57 & 18.69 & 19.36 \\
& $30-\mathrm{m}$ & 36.79 & 36.88 & 34.98 & 31.94 \\
Temperature (Unit: $\left.{ }^{\circ} \mathrm{C}\right)$ & Surface & 1.45 & 1.67 & 1.64 & 1.63 \\
& $2-\mathrm{m}$ & 1.20 & 1.11 & 1.06 & 1.24 \\
& $10-\mathrm{m}$ & 1.15 & 1.08 & 1.03 & 1.21 \\
& $20-\mathrm{m}$ & 1.10 & 1.10 & 0.98 & 1.32 \\
& $30-\mathrm{m}$ & 1.04 & 1.04 & 0.77 & 1.15 \\
\hline
\end{tabular}



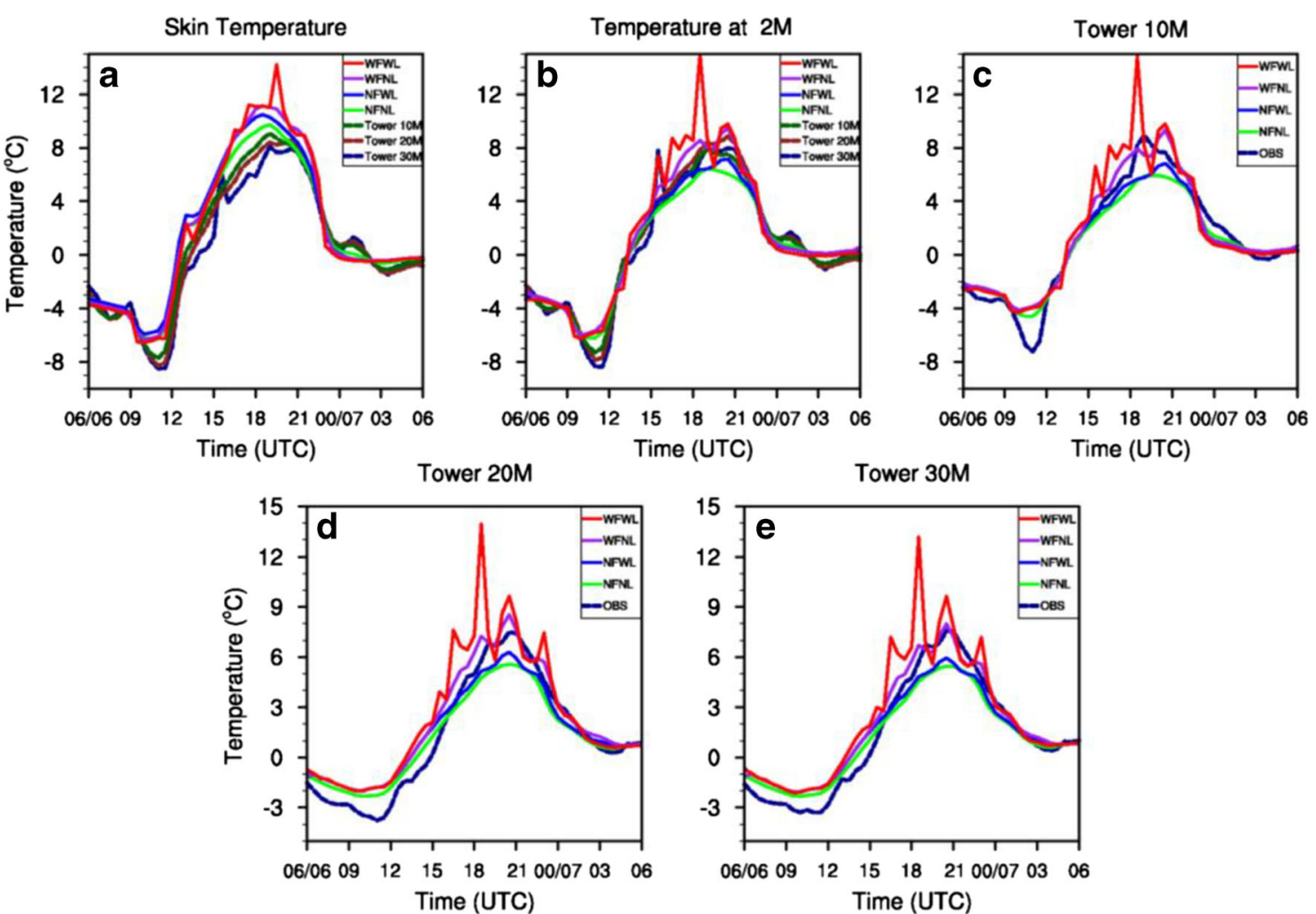

Tower 30M

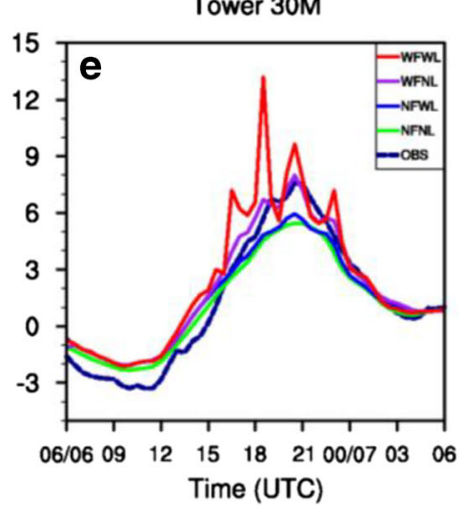

Fig. 6 The temperatures comparison of observations (dot line) and simulated cases (solid line) at the surface (a), $2 \mathrm{~m}(\mathbf{b}), 10 \mathrm{~m}(\mathbf{c}), 20 \mathrm{~m}(\mathbf{d})$ and $30 \mathrm{~m}(\mathrm{e})$ AGL

dynamic instability. Sun et al. (2009) coupled the wildland fire with a simple operational fire behavior model in the LES mode to examine differences in the rate of spread and the area burned by a grass fire for two atmospheric boundary layer (ABL) types: the convective boundary layer $(\mathrm{CBL})$ and the roll-dominated boundary layer (RBL). Their results showed the pattern of the spread of the fire in the buoyancy-dominated or roll-dominated ABL and the importance of fire-atmosphere coupling to the spread of the fire line. The fire heat fluxes were inserted into the lowest layer of the atmospheric model as forcing terms in the model equations, with an assumed altitude exponential decay (Mandel et al. 2011). The in-draft flow contributed greatly to extend the fire height by introducing a large amount of fresh oxygen to the burning region. Asymmetrical inflow air also accelerate the spread of fire (Viegas and Pita 2004). Eventually, the indraft flow developed into a tilted fire-induced convective column near the flame and titled downstream with height by the ambient winds. When the fire grew large enough, it began to produce its own climate and suck fresh air toward the fire core to replace the hot air rising above the flame (Sun et al. 2009).

Figure 9 shows the sensible heat fluxes released from the wildland fire, the differences of the surface temperature and $10 \mathrm{~m}$ wind at variant times between WFWL and NFWL case. It is easy to see the variations of the winds, temperatures and some elements caused by the wildland from the figure. At 16:00 (Fig. 9a), which is $1 \mathrm{~h}$ after the ignition, the fire begins to spread to the southeast, and the maximum sensible heat fluxes released by the fuel combustion are approximately $1.5 \times 10^{4} \mathrm{~W} \mathrm{~m}^{-2}$. Correspondingly, there is a positive temperature region in narrow and long shape with the center over $3.5{ }^{\circ} \mathrm{C}$ due to the releasing of the heat flux along the northwesterly ambient flow. The region of the positive temperature is located ahead of the heat flux center, and the magnitude of the temperature increment decreased with the distance from the heat flux center. These results are consistent with the results of Clark et al. (1996b).

Meanwhile, the heat released by the fuel combustion increase the vertical buoyancy, accelerate the updraft, and destroy the stability near the surface. As Fig.10a shows, there is a horizontal convergence region in the leeward of the fire front, and the intensity of convergence in wind speed is about $2 \mathrm{~m} \mathrm{~s}^{-1}$ in the downstream of the heat flux center. The vertical velocity of updraft is about $0.8 \mathrm{~m} \mathrm{~s}^{-1}$ (Fig. 10a). When the ambient flows shift northward at 20:30 (Fig. 10b), the combustions reach the most robust stage. The sensible heat fluxes releasing from the fire are greater than $2.0 \times 10^{4} \mathrm{~W} \mathrm{~m}^{-2}$ with the temperature increment center larger than $4.5^{\circ} \mathrm{C}$ and stretch to the downwind region about $1 \mathrm{~km}$ away from the fire region. The horizontal convergent velocity is considerably greater 
Fig. 7 The heat flux released from the fire (counter), the ambient flow (vector) and the vertical velocity (shaded) at (a) 16:00, b19:00, c20:30, and $\mathbf{d}$ is the fire perimeters of WFWL case at 16:00 (pink), 17:00 (brown), 18:00 (green), 19:00 (blue), 20:30 (white) respectively, and distribution of all the observation position (markets)
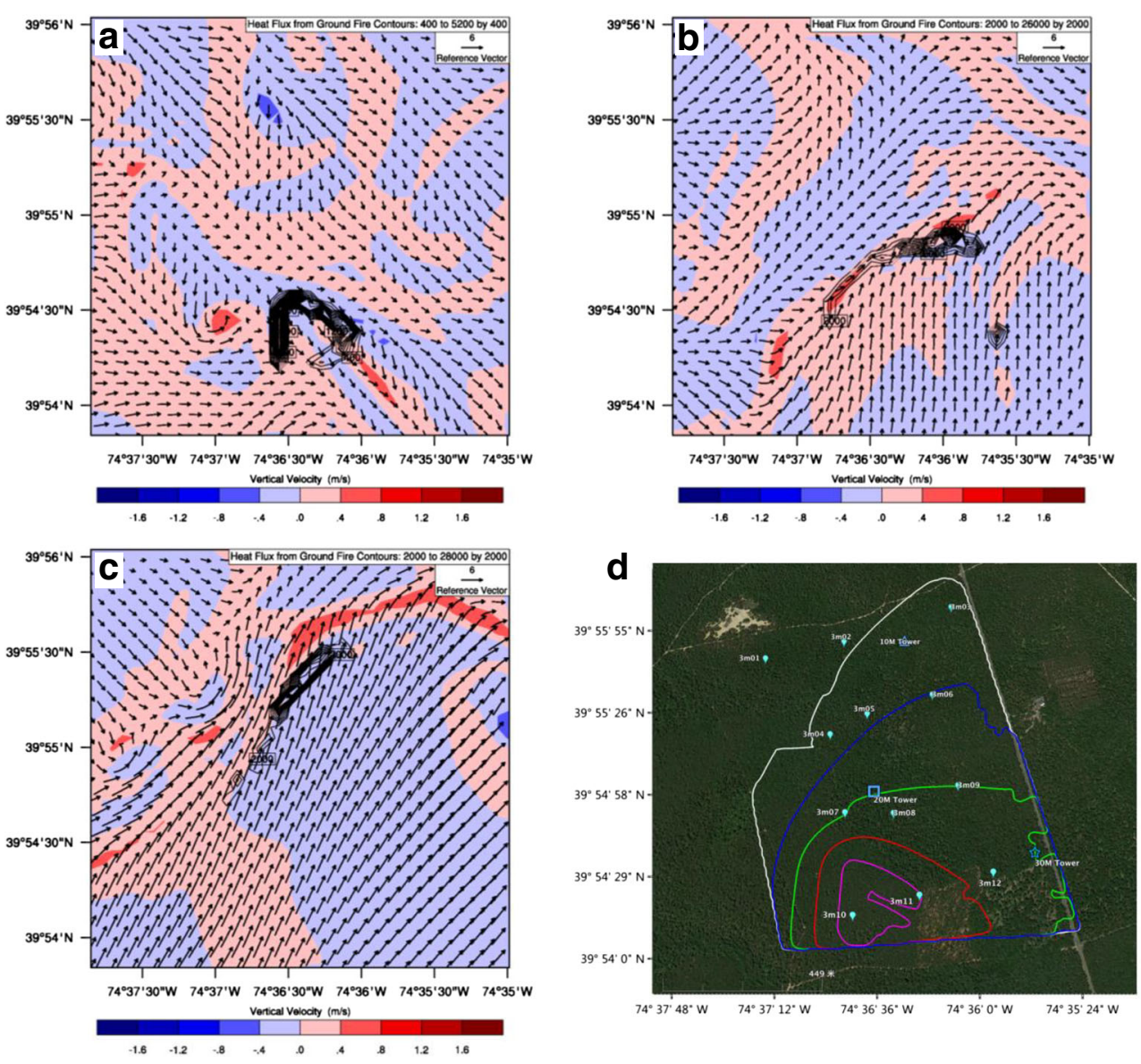

than $5 \mathrm{~m} \mathrm{~s}^{-1}$, and the vertical velocity is larger than $1.6 \mathrm{~m} \mathrm{~s}^{-1}$ (Fig. 10b).

From the fig. 10, there are downdrafts and divergent regions on both side of the updraft region. It proves that the WRF-Fire model in LES mode of LIPF experiment can also generate the horizontal convective rolls to transport momentum, heat, et al.

From the crosssection of fire region (Fig. 11), the alternating updrafts and downdrafts on both sites of the combustion zone are organized parallel to the mean ambient wind. The fire's pumping greatly enhanced the updraft, and a downdraft also transported higher-momentum air from the upper levels to the surface levels behind the fire line, which increased the winds ahead of the fire line and developed into a vertical circulation like a series of parallel rolls, the HCRs, lateral to the fire area. The increased wind ahead of the fire line magnified the TKE near the fire's flame and caused the fire to burn a larger area. Figure 8 shows the different sections of simulated temperature, wind and TKE along the latitudes (line A1-A2 in Fig.9a) and longitudes (line B1-B2 in Fig. 9b) between the areas that were ablaze at the two times. Figure $11 \mathrm{a}$ is the latitude cross-section along A1-A2. In the figure, the wind perturbation was aligned with the center of the temperature variation, and there are multiple sub-centers of TKE that were located on the both sides of the fire, especially along the direction of the spread of the fire. With the help of the turbulences that were induced by fire, the TKE can stretch to a height of approximately $100 \mathrm{~m}$. As the flame developed and the wildland fire became fully developed at 20:30 UTC (Fig. 11b), there was a wide range of maximum TKE adjacent and downstream of the fire line. However, the TKE was restrained from stretching to a higher level by the strong downdraft and only reached a height of $60 \mathrm{~m}$. With the consumption of the fuels, the fire gradually extinguished, and the height of the spread of the TKE also decreased (not shown).

From Figs. 10 and 11, it is clear that, as the fire grows, the more sensible heat flux fire releases, the greater thermal and dynamical instability the atmospheric stratification produces, and the stronger interactions between the fire and the atmosphere near the surface, finally, the fire induced climate will promote the combustion of wildland fire. In these interactive circumstances, the particles and heat from the combustion of the fuel will be transported further, both downwind and to the lateral regions of the fire by the fire-induced convection and the HCRs that are generated by the high thermal and dynamic instability, which may have important effects on the diffusion of tiny particles and human health. 

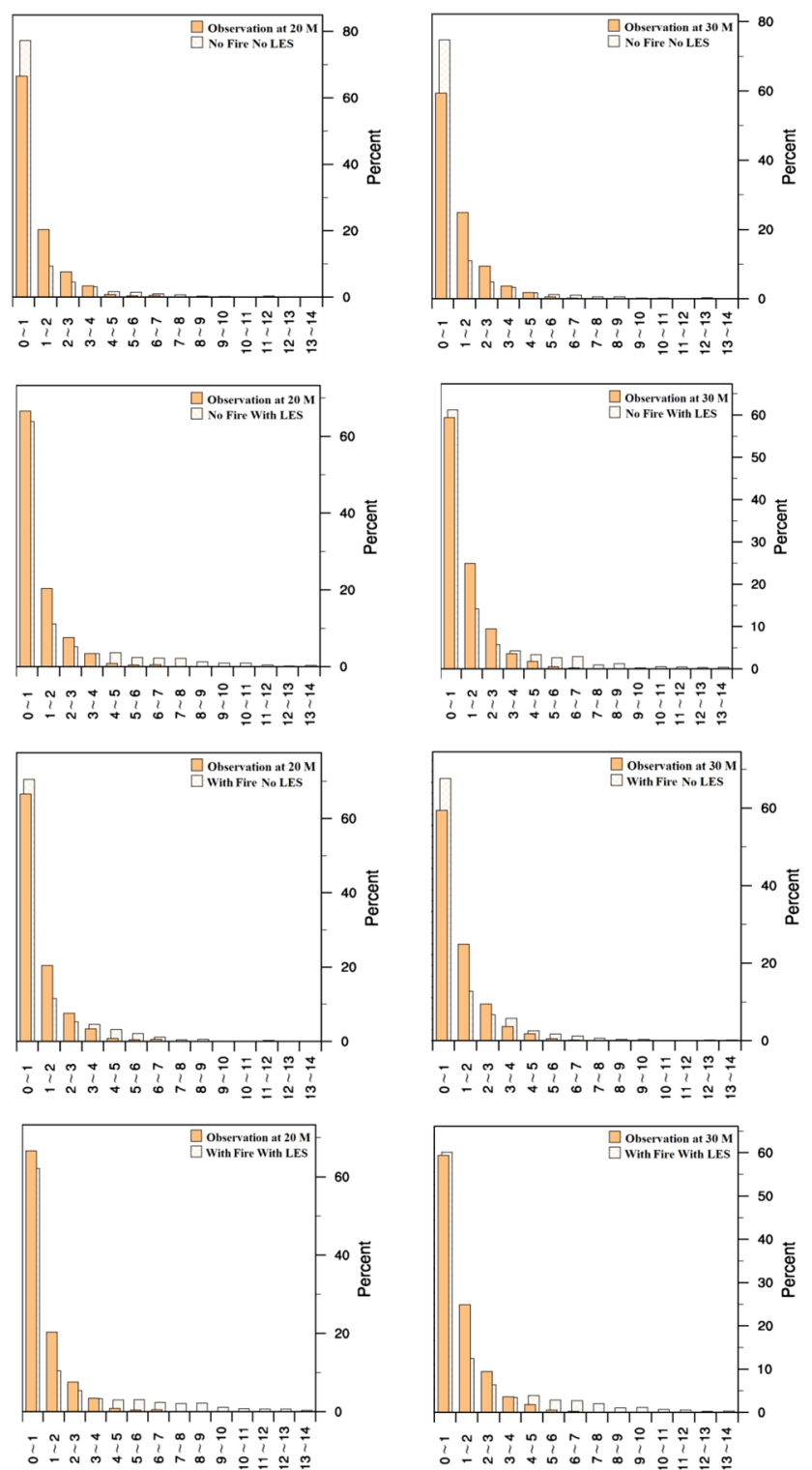

$\operatorname{TKE}\left(\mathrm{m}^{2} \cdot \mathrm{s}^{-2}\right)$

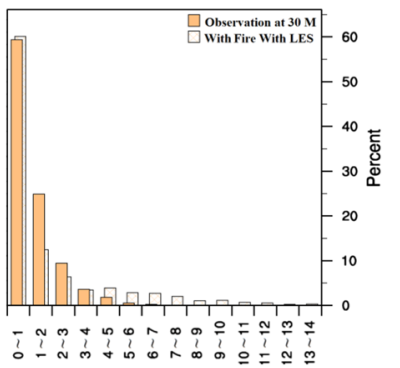

$\operatorname{TKE}\left(\mathrm{m}^{2} \cdot \mathrm{s}^{-2}\right)$

Fig. 8 Comparisons of simulated distribution histograms of TKE (unit: $\mathrm{m}^{2} \mathrm{~s}^{-2}$ ) with the observations at $20 \mathrm{~m}$ (left column) and $30 \mathrm{~m}$ (right column) AGL. The frequency is calculated based on 1-min mean TKE for the entire fire period from 06:00 UTC, Mar 6 to 06:00 UTC, Mar 7, 2012

\section{Discussions and Conclusions}

A series of evaluations are conducted using the highresolution WRF-Fire simulation and various measurements collected from the LIPF experiment. Numerical sensitive simulations using the WRF-Fire coupled model system not only give reasonable results matching observations, but also can reveal detailed interactions between the fire-induced climate and atmosphere near the surface, especially for WRF-Fire in the LES mode.
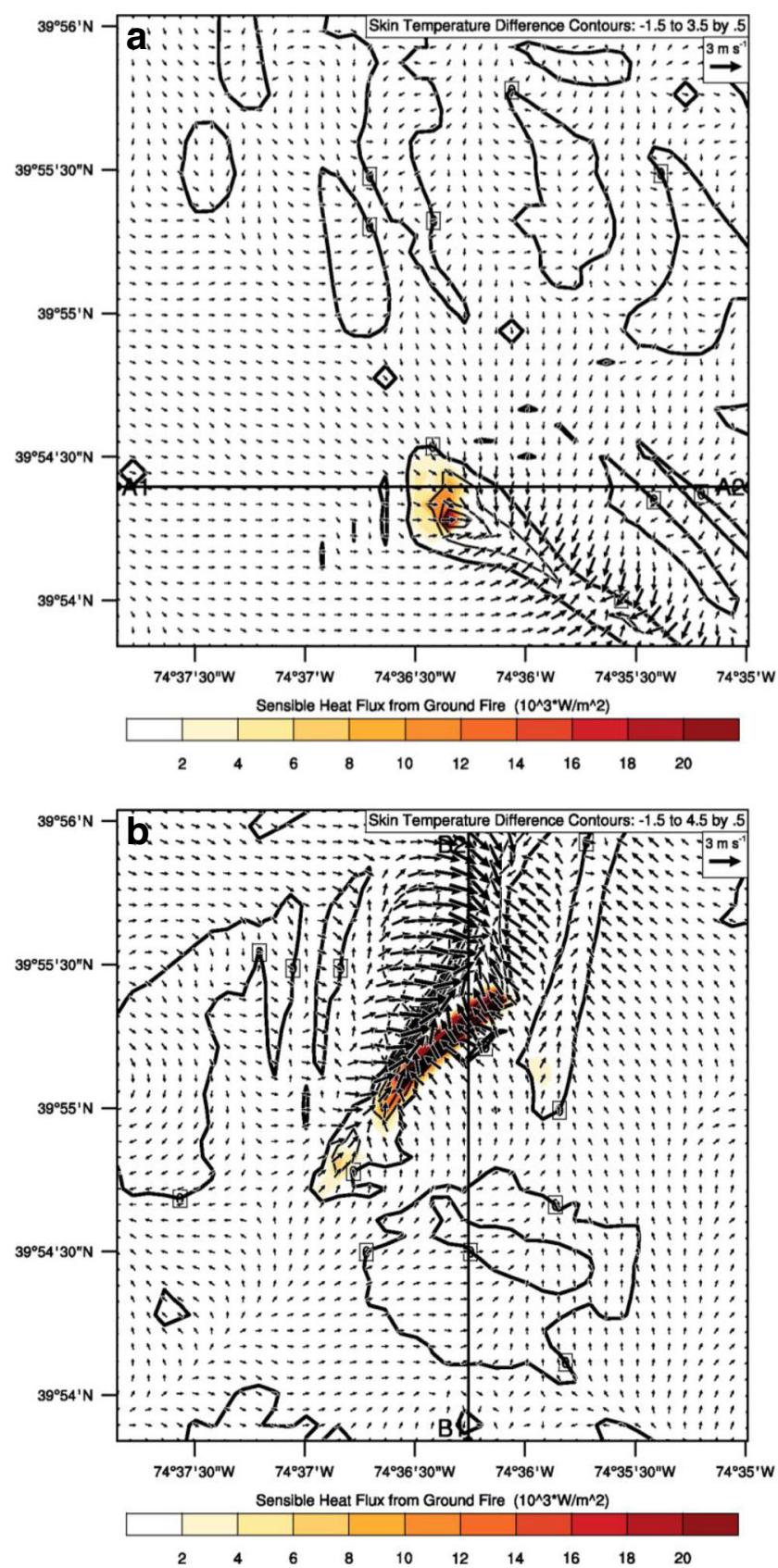

Fig. 9 The sensible heat flux (shaded, unit: $10^{3} \times \mathrm{W} \mathrm{m}^{-2}$ ) released from the wildland fire, and the difference of surface temperature (contour, unit: ${ }^{\circ} \mathrm{C}$ ) and $10 \mathrm{~m}$ wind (vector, unit: $\mathrm{m} \mathrm{s}^{-1}$ ) at variant times between WFWL and NFWL. a 16:00, b 20:30

The WRF-Fire captures the profiles of wind and temperature shifting at different times, particularly, the simulated vertical inversion profiles matching the observations well. The model provides reasonable wind speed and wind direction comparing with the observations at $20 \mathrm{~m}$ and $30 \mathrm{~m}$ height. The simulated temperatues and drew-point temperatures are closed to the observations, espercially in higher levels. There exhibits more perturbations and peaks with the increasing of height, especially in WFWL case. 

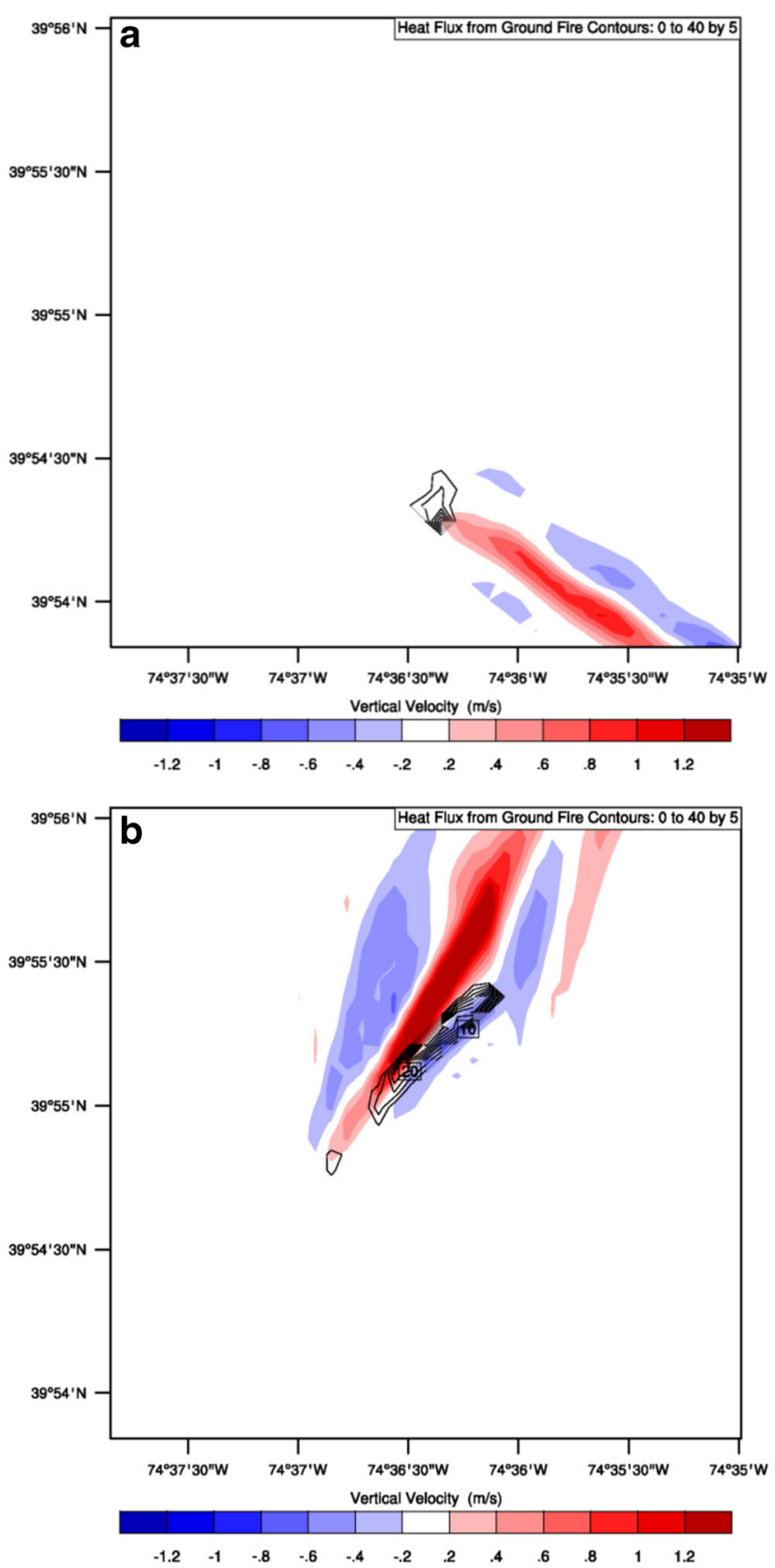

Fig. 10 The difference of vertical velocity (shaded, unit: $\mathrm{m} \mathrm{s}^{-1}$ ) and sensible heat flux (contour, unit: $10^{3} \times \mathrm{W} \mathrm{m}^{-2}$ ) between WFWL and NFWL simulation at variant times. a 16:00, b 20:30

The ambient wind near the surface is one of the most critical factors for wildland fire simulations because it restricts the direction and speed of the fire spread and the combustion of fuels in WRF-Fire. The temperatures within the burning area simulated by WRF-Fire, particularly in the LES mode, are consistent with the observational measurements, but with more peaks and perturbations by the influence of the fuel combustion.

Moreover, the WRF-Fire model exhibits the details of interactions between the $\mathrm{ABL}$ and fire-induced climate. As the

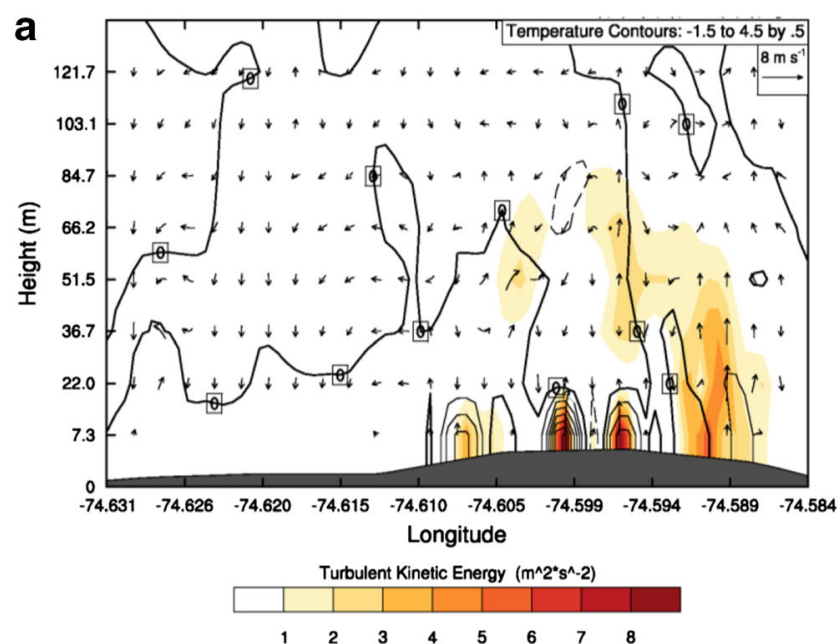

b

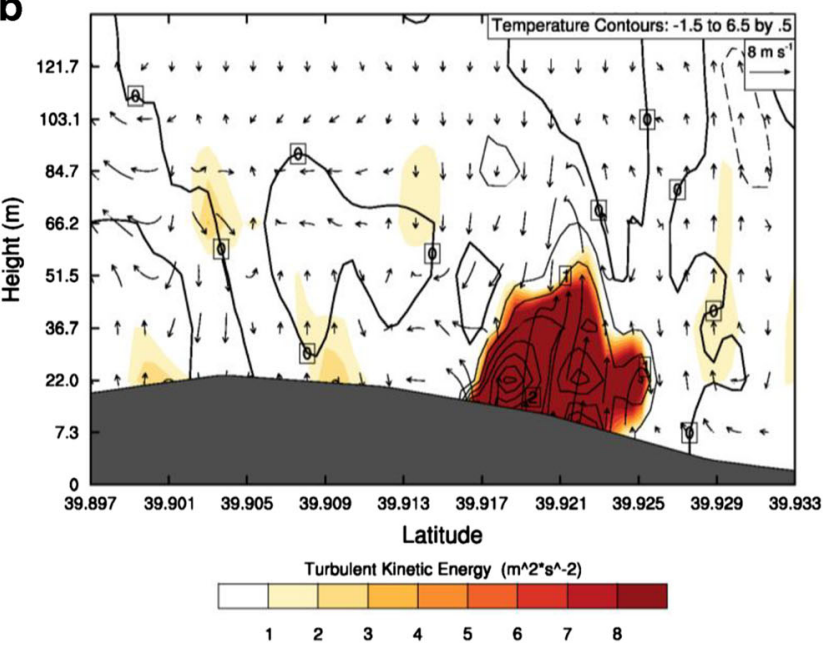

Fig. 11 The difference of temperature (contour, unit: ${ }^{\circ} \mathrm{C}$ ), wind (vector, unit: $\mathrm{m} \mathrm{s}^{-1}$ ) and turbulent kinetic energy (shaded, unit: $\mathrm{m}^{2} \mathrm{~s}^{-2}$ ) in the longitude and latitude profile section across the fire region between WFWL and NFWL at times of (a) 16:00, b 20:30. a is a latitude section, and $\mathbf{b}$ is a longitude section

fire growing, a great amount of sensible heat flux is released from the combustion of fuels and heats the air near the surface. The heated air near the surface is the source of the strong updrafts. Simultaneously, there are downdrafts on lateral of the fire area, which transport the air with higher-momentum from upper to surface, to compensate the upward flow and increase the wind speeds and the convergence near the fire line. The fire induced updraft together with the compensating downdrafts develope into a vertical circulation like a series of parallel rolls, HCRs, which is the formation processes of fireinduced climate. The updraft will be tilted to downstream with height by the ambient winds, and transport the large quantity of particles and the heat released from the fire to downwind and to lateral areas far away from the fire region.

This paper is based on the WRF model coupled with a fire module by the data collect from LIPF experiment. The data are gathered from variant instruments at different locations, 
where the, The results indicate that the WRF-Fire model in the LES mode can be used as a wildland fire behavior operational forecast model, but there is still much work to be done, including physical parameterizations, improving the model performance with grid spacing of hundreds or tens of meters (or even finer resolutions), and especially the improving the fire descriptive module. This work will be accomplished in future research.

Acknowledgments The authors would like to extend their sincere gratitude to S. Zhong, CGCEO, Geography Department, MSU, and X. Bian, USDA Forest Service, for providing observational data of the LIPF experiment and for their instructive advice on this paper. This study has been jointly supported by NSFC (41230422 and 41475083), NCET Program, the Natural Science Foundation of Jiangsu Province of China under Grant No. BK2004001 and Project Funded by the Priority Academic Program Development of Jiangsu Higher Education Institutions (PAPD).

Open Access This article is distributed under the terms of the Creative Commons Attribution 4.0 International License (http:// creativecommons.org/licenses/by/4.0/), which permits unrestricted use, distribution, and reproduction in any medium, provided you give appropriate credit to the original author(s) and the source, provide a link to the Creative Commons license, and indicate if changes were made.

\section{References}

Anderson HE (1982) Aids to determining fuel models for estimating fire behavior. US Department of Agriculture Forest Service, General Technical Report INT-122

Chen, F., Dudhia, J.: Coupling an advanced land surface-hydrology model with the Penn State-NCAR MM5 modeling system. Part I: model implementation and sensitivity. Mon. Wea. Rev. 129, 569-585 (2001)

Clark, T.L., Jenkins, M.A., Coen, J., Packham, D.: A coupled atmospheric-fire model: convective feedback on fire line dynamics. J. Appl. Meteorol. 35, 875-901 (1996a)

Clark, T.L., Jenkins, M.A., Coen, J.L., Packham, D.R.: A coupled atmosphere-fire model: role of the convective froude number and dynamic fingering at the fireline. Int. J. Wildland Fire. 6, 177-190 (1996b)

Clark, T.L., Coen, J., Latham, D.: Description of a coupled atmospherefire model. Int. J. Wildland Fire. 13, 49-64 (2004)

Coen, J.L.: Simulation of the big elk fire using coupled atmosphere-fire modeling. Int. J. Wildland Fire. 14, 49-59 (2005)

Coen, J.L., Cameron, M., Michalakes, J., Patton, E.G., Riggan, P.J., Yedinak, K.M.: WRF-fire: coupled weather-Wildland fire modeling with the weather research and forecasting model. J. Appl. Meteor. Climatol. 52, 16-38 (2013)

Deardorff, J.W.: Numerical investigation of neutral and unstable planetary boundary layers. J. Atmos. Sci. 29, 91-115 (1972)

Deardorff, J.W.: Three-dimensional numerical study of turbulence in an entraining mixed layer. Bound.-Layer Meteor. 7, 199-226 (1974)

Dudhia, J.: Numerical study of convection observed during the winter monsoon experiment using a mesoscale two-dimensional model. J. Atmos. Sci. 46, 3077-3107 (1989)
Heilman, W.R., Bian, X.: Turbulent kinetic energy during wildfires in the north central and north-eastern US. Int. J. Wildland Fire. 19, 346$363(2010)$

Heilman, W. E., and Coauthors (2013) Development of modeling tools for predicting smoke dispersion from low-intensity fires. Joint Fire Science Plan Study Final Rep. 09-1-04-1, 64 pp. [Available online at https://www.firescience.gov/projects/09-1-04-1/project/09-1-04-1_ final_report.pdf]

Hong, S.Y., Dudhia, J., Chen, S.H.: A revised approach to icemicrophysical processes for the bulk parameterization of cloud and precipitation. Mon. Wea. Rev. 132, 103-120 (2004)

Hunt, S.M., Simpson, J.A.: Effects of low intensity prescribed fire on the growth and nutrition of slash pine plantations. Aust For Res. 15(1), 67-77 (1985)

Janjic, Z.I.: The step-mountain coordinate: physical package. Mon. Wea. Rev. 118, 1429-1443 (1990)

Janjic, Z.I.: The step-mountain eta coordinate model: further developments of the convection, viscous layer, and turbulence closure schemes. Mon. Wea. Rev. 122, 927-945 (1994)

Janjic ZI (2001) Nonsingular implementation of the Mellor-Yamada level 2.5 scheme in the NCEP Meso model. NOAA/NWS/NCEP office note 437 , pp 61

Jiménez, P.A., Dudhia, J.: Improving the representation of resolved and unresolved topographic effects on surface wind in the WRF model. J. Appl. Meteor. Climatol. 51, 300-316 (2012)

Kain, J.S.: The Kain-Fritsch convective parameterization: an update. J. Appl. Meteorol. 43, 170-181 (2004)

Kondratenko V Y, Beezley J D, Kochanski A K, et al. (2011) Ignition from a Fire Perimeter in a WRF Wildland Fire Model

Mandel, J., Beezley, J.D., Coen, J.L., Kim, M.: Data assimilation for Wildland fires: ensemble Kalman filters in coupled atmosphere-surface models. IEEE Control. Syst. Mag. 29, 4765 (2007)

Mandel, J., Beezley, J.D., Kochanski, A.K.: Coupled atmospherewildland fire modeling with WRF-fire version 3.3. Geosci. Model Dev. Discuss. 4, 497-545 (2011)

Mandel, J., Amram, S., Beezley, J.D., et al.: Recent advances and applications of WRF-SFIRE. Nat. Hazards Earth Syst. Sci. 14(10), 2829-2845 (2014)

Mason, P.J.: Large-eddy simulation of the convective atmospheric boundary layer. J. Atmos. Sci. 46, 1492-1516 (1989)

Mell, W., Jenkins, M.A., Gould, J., Cheney, P.: A physics-based approach to modelling grassland fires. Int. J. Wildland Fire. 16, 1-22 (2007)

Mesinger, F., DiMego, G., Kalnay, E., Mitchell, K., Shafran, P.C., Ebisuzaki, W., Jović, D., Woollen, J., Rogers, E., Berbery, E.H., Bk, M., Fan, Y., Grumbine, R., Higgins, W., Li, H., Lin, Y., Manikin, G., Parrish, D., Shi, W.: North American regional reanalysis. Bull. Amer. Meteor. Soc. 87, 343-360 (2006)

Mlawer, E.J., Taubman, S.J., Brown, P.D., Iacono, M.J., Clough, S.A.: Radiative transfer for inhomogeneous atmospheres: RRTM, a validated correlated-k model for the longwave. J. Geophys. Res. 102D, 16663-16682 (1997)

Moeng, C.H.: A large-eddy-simulation model for the study of planetary boundary layer turbulence. J. Atmos. Sci. 41, 2052-2062 (1984)

Moeng, C.-H., J. Dudhia, J. Klemp, and P. Sullivan.: Examining two-way grid nesting for large eddy simulation of PBL using the WRF model. Mon. Wea. Rev., 135, 2295-2311 (2007)

Morvan D, Tauleigne V, Dupuy JL (2002) Wind effects on wildfire propagation through a Mediterranean shrub. Forest fire research and wildland fire safety: Proceedings of IV International Conference on Forest Fire Research 2002 Wildland Fire Safety Summit, Luso, Coimbra, Portugal 
Patton EG, Coen JL (2004) WRF-fire: a coupled atmosphere-fire module for WRF. Preprints of joint MM5/weather research and forecasting model Users' workshop, NCAR, Boulder, CO, pp 221-223

Skamarock WC, Klemp JB, Dudhia J, Gill DO, Barker DM, Duda MG, Huang XY, Wang W, Powers JG (2008) A description of the advanced research WRF version 3. NCAR technical note 475

Sun, R., Jenkins, M.A., Krueger, S.K., Mell, W., Charney, J.: An evaluation of fire-plume properties simulated with the fire dynamics simulator (FDS) and the Clark coupled wildfire model. Canadian J. Forestry Research. 36, 2894-2907 (2006)

Sun, R., Krueger, S.K., Jenkins, M.A., Zulauf, M.A., Charney, J.: The importance of fire-atmosphere coupling and boundary-layer turbulence to wildfire spread. Int. J. Wildland Fire. 18, 50-60 (2009)
USDA Forest Service (1989) A guide for prescribed burning in Southern Forest. USDA Forest Service- Southern Region R8 -TP 11: 56P

Viegas, D.X., Pita, L.P.: Fire spread in canyons. Int. J. Wildland Fire. 13, 253-274 (2004)

Weckwerth, T.M., Wilson J.W., Wakimoto R.M., Crook, N.A.: Horizontal convective rolls: Determining the environmental conditions supporting their existence and characteristics. Mon. Wea. Rew., 125, 505-526 (1997)

Publisher's Note Springer Nature remains neutral with regard to jurisdictional claims in published maps and institutional affiliations. 